\title{
The design and evaluation of psychometric properties for a questionnaire on elderly abuse by family caregivers among older adults on hemodialysis
}

This article was published in the following Dove Press journal:

Clinical Interventions in Aging

\author{
Amaneh Mahmoudian' \\ Razieh Torabi Chafjiri ${ }^{2}$ \\ Atefeh Alipour ${ }^{3}$ \\ Abbas Shamsalinia ${ }^{4}$ \\ Fatemeh Ghaffari ${ }^{5}$ \\ 'Nursing Care Research Center, \\ Health Research Institute, Babol \\ University of Medical Sciences, \\ Babol, Iran; ${ }^{2}$ Guilan University of \\ Medical Sciences, Rudsar Shahid \\ Ansari Hospital, Rudsar, Guilan, Iran; \\ ${ }^{3}$ Mazandaran University of Medical \\ Sciences, Imam Sajjad Hospital, \\ Ramsar, Mazandaran, Iran; ${ }^{4}$ Nursing \\ Care Research Center, Health \\ Research Institute, Babol University \\ of Medical Sciences, Babol, Iran; \\ ${ }^{5}$ Nursing Care Research Center, \\ Health Research Institute, Babol \\ University of Medical Sciences, \\ Babol, Iran
}

Introduction: Older adults with chronic disease are more vulnerable to abuse. Early and accurate detection of the elderly abuse phenomenon can help identify health-promoting solutions for the elderly, their family, and society. The purpose of this study was to design and evaluate the psychometric properties of a questionnaire on elderly abuse by family caregivers among older adults on hemodialysis.

Methods: Qualitative and quantitative research methodologies were used to develop the questionnaire. The item pool was compiled from literature reviews and the Delphi method. The literature reviews comprised 22 studies. The psychometric properties of the questionnaire were verified using face, content, and construct validity, and the reliability was tested using Cronbach's alpha reliability.

Results: A 57-item questionnaire was developed after the psychometric evaluation. The Kaiser-Meyer-Olkin index and Bartlett's test of sphericity showed reliable results. Seven components from the exploratory content analysis including psychological misbehavior, authority deprivation, physical misbehavior, financial misbehavior, being abandoned, caring neglect, and emotional misbehavior explained $74.769 \%$ of the total variance. Cronbach's alpha was 0.98 and the interclass correlation coefficient was $r=0.91$ responding to the items twice $(p<0.001)$, which shows a high level of tool stability.

Conclusion: This study developed a questionnaire to assess elderly abuse by family caregivers among older adults on hemodialysis. It is recommended as a mini scale that can be used both in statistical and practical studies, and that is valid and reliable. Nurses or other health care providers can use it in health centers, dialysis centers, or at the house of the patient.

Keywords: elderly abuse, family caregivers, older adults, hemodialysis, reliability, validity, psychometric testing

\section{Introduction}

The older population - persons 65 years or older - is estimated to double in the next 40 years as the global numbers grow rapidly. The percent of elderly will reach $52 \%$ in Asian countries and 40\% in developed countries. ${ }^{1}$ As a developing country, Iran will be affected by this growth. The census records of 2011 show that $8.24 \%$ of the country's population is old, and it is estimated that the number would grow to $10 \%$ by $2021 .^{2}$ A vast number of the elderly need health care due to having chronic illnesses, ${ }^{1}$ and chronic renal failure is among the top problems faced by the elderly. ${ }^{3}$

Chronic renal disease is a major health concern that incurs poor health consequences and high health care costs, with a greater prevalence among the elderly. ${ }^{4}$ In the last two decades, the number of elderly patients with chronic renal failure has
Correspondence: Fatemeh Ghaffari Nursing Care Research Center, Health Research Institute, Babol University of Medical Sciences, Shahid Motahari St, Ramsar, Babol 46917-14141, Mazandaran, Iran

Tel +98 II 55225 I5I

Email ghafarifateme@yahoo.com 
increased in most countries. Hence, in terms of age pattern, this disease has been inclined toward the elderly. ${ }^{5}$ As in other age groups, dialysis-dependent renal failure has consistently increased among elderly people over the last decade. ${ }^{6}$

Patients with end stage chronic renal failure need alternative treatments such as hemodialysis and kidney transplantation. ${ }^{7}$ The hemodialysis patients' caregivers may be faced with several problems and stress factors owing to the vast caring needs which threaten both the patient and the caregivers' health. The caring needs of these elderly patients rise as the treatment process starts due to self-care problems, financial problems, not being able to control the disease and the treatment process, undergoing procrustean treatments, having limitations owing to strict treatment regimens, getting other chronic illnesses like chronic artery disease or diabetes, changes in self-image, unstable job positions, and the insufficiency of multi-aspects of social support. ${ }^{8}$ One other problem which they may suffer from is abuse by caregivers. ${ }^{9}$

It is estimated that $4 \%-10 \%$ of elderlies ( 65 years or older) are abused by relatives, caregivers, or others. ${ }^{10}$ The prevalence of elderly abuse by family caregivers is reported to be $12 \%-15 \% .^{11}$ There is no data on the elderly abuse among the patients on hemodialysis though it is believed that such a phenomenon is prevalent in this group of elderlies. ${ }^{12}$

Findings in many empirical studies suggest that physical stressors such as chronic illnesses and activities of daily living limitations were significantly associated with the degree of elderly abuse. ${ }^{13}$ Poor health and limited functional ability, particularly in regard to self-care, were strongly correlated with elderly abuse occurring in community settings. ${ }^{14}$ In addition, older adults with one or more physical impairments (health problems) were more vulnerable to abuse because of their diminished ability to protect themselves and their dependence on the caregiver. ${ }^{15}$

There is a paucity of studies in this area despite the WHO's emphasis on international awareness regarding the recognition and prevention of abuse of the elderly, ${ }^{16}$ as abuse could lead to a decrease in self-confidence, feelings of disappointment and incompetence in self-care, stopping the treatment process, and an increase in depression and helplessness among the elderly, particularly those having chronic illnesses. Recognizing the elderly abuse phenomenon is based on nonspecific and general factors using current tools. There is no available instrument to specifically evaluate the elderly abuse in patients on hemodialysis. Early and accurate detection can help elderlies, their family, and society by finding health-promoting solutions. Therefore, the purpose of this study was to design and evaluate psychometric properties for a questionnaire on elderly abuse by family caregivers among older adults on hemodialysis.

\section{Methods}

Research methodology for designing and evaluating the data-gathering tools ${ }^{17}$ was adopted to develop the questionnaire of abuse of elderlies undergoing dialysis by family caregivers. The Rand Delphi method was used to identify content appropriate for the first step. ${ }^{18}$ It is an approach or a systematic method where the comments of experts regarding a subject or area to be studied can be identified. ${ }^{19}$

The designation of the questionnaire was done using the modified Delphi classic method. ${ }^{18}$ The research community consisted of faculty members (with at least 5 years of educational experience) and nurses in clinical settings (with at least 5 years of clinical experience and caring for hemodialysis patients) working in Tehran, Iran, and Babol universities of medical sciences or the treatment centers under their control.

One of the research group members contacted the faculty member participants by e-mail and the nurses in person and gave them the needed information about the nature of a Delphi study, the aim of the research, the importance of their participation in exploring the factors related to elderly abuse, and requested their voluntary cooperation. The level of expertise, quality, and panel composition in the Delphi method are more important than the number of participants, and there are regularly less than 50 and generally 15-20 participants reported in the studies using this method. ${ }^{18,20}$ The groups comprising the panel were selected as the research community. Sampling was done after the determination of the statistical society owing to having a heterogeneous research community. The sampling of each group was based on the purposive sampling technique. ${ }^{21}$

The sample size was set to be 21 which decreased to 17 participants after inviting them and giving them the final information about the research and the regulations. Extensive searches were conducted for clarifying the research concept in literature reviews where several keywords, such as elderly abuse, chronic illnesses, end-stage renal disease, tool design, and psychometric tests were searched in Scopus, Ovid, ProQuest, Science Direct, PubMed, and CINHAL databases without setting any specific time limit for the literature search. Finally, 22 papers were selected for the study. Textual content analysis was used for analyzing the papers, and the data 
analysis process involved a thorough review of the papers. The result of this extensive review was a list of items for the final data check.

The early questionnaire was prepared in the first Delphi round after the research team applied the needed modifications and changes. It consisted of various sections including an introduction to the research, the research aims, the answering guide of the four-point Likert scale (from never to always), the personal information of the expert panel, and 74 structural questions in eight components of "sexual misbehavior" (4 items), "caring neglect" (9 items), "psychological misbehavior" (9 items), "physical misbehavior" (4 items), "financial misbehavior" (13 items), "authority deprivation" (7 items), "being abandoned" (4 items), and "emotional misbehavior" (23 items). There was also an open-ended question requesting the participants to give their suggestions and comments for improving the items and the components of the questionnaire.

The first Delphi round: the expert panel members were requested to announce their agreement on the items according to the five-point Likert scale (strongly disagree $=1$ to strongly agree $=5$ ) by scoring each item and giving their suggestions and comments for improving the items by answering the open-ended question.

The statistical analysis of the answers was done by calculating the measures of central tendency and the dispersion index. The interquartile range, mean, and the SD of each item were also measured..$^{20}$ The level of statistical significance was at $p<0.05$. SPSS software, version 19 (SPSS Inc., Chicago, IL, USA) and Lisrel 8 Scientific Software International, Inc. were used for the data analyses.

The items with the percentile of 75 or more were accepted to be included in the questionnaire while those with the percentile of 25 or less were omitted. The items between the percentiles of 25 and 75 were retained for the second Delphi round.

The second Delphi round: a draft of the questionnaire designed in the first round was sent to the expert panel members, who participated in the first round, by e-mail and they were asked to declare their agreement with the items as they had before. The majority of the professionals believed that an agreement on $80 \%$ of the items establishes reaching a consensus. ${ }^{22}$

Therefore, the items with an agreement level of $70 \%-80 \%$ or more with a score change less than 15 were accepted. The study was conducted with two Delphi rounds as no item with an agreement level of $75 \%$ or more and score change of more than 15 were retained. ${ }^{23}$ Finally, the current questionnaire with 63 items and 7 components was ready for the psychometric process.

\section{Face validity}

The face validity was tested by both qualitative and quantitative methods. It is considered as a degree in which the questionnaire appears effective in terms of its stated aims, qualitatively. Ten elderlies referred by the health centers for hemodialysis were asked to comment on difficulty, relevancy, and ambiguous levels in face-to-face interviews to qualitatively test the face validity. Afterward, the item impact method was applied to decrease or eliminate the inappropriate items and determine each item's importance in a quantitative method. A five-point Likert scale (absolutely important to absolutely unimportant) was used to study each item, and the same elderlies were asked to determine the importance of each item according to their experience. The least point was set to be 1.5 , and any item receiving it or less was eliminated from the questionnaire. ${ }^{24}$

\section{Content validity}

Both qualitative and quantitative methods were employed to determine the content validity. Eight nursing lecturers with sufficient working experience in the clinical, theoretical, and research settings were asked to comment on the grammar, wording, allocation, and scaling of the items. Two indices of content validity index (CVI) and content validity ratio (CVR) were used to quantitatively test the content validity of the items.

\section{Content validity ratio}

Lawshe model was used to determine the $\mathrm{CVR}^{25}$ in this study. Eight subject experts (nursing faculty members with the working experience in clinical settings, tool making, and teaching nursing subjects regarding the elderly) were asked to determine the necessity of each item according to a threepoint scale including necessary, helpful but not necessary, and unnecessary.

CVR varies between +1 and -1 . The higher score indicates further agreement of members of the panel on the necessity of an item in an instrument. The formula of CVR is $C V R=(\mathrm{Ne}-\mathrm{N} / 2) /(\mathrm{N} / 2)$, where $\mathrm{Ne}$ is the number of panelists indicating "essential" and $\mathrm{N}$ is the total number of panelists. The numeric value of the CVR is determined by Lawshe table.

The minimum value of CVR according to the Lawshe's table and the number of experts (all responded to the questions) was set to 0.75 . The item was considered necessary 
with a statically significant level $(p<0.05)$ if the outcome number was larger than the table's number. ${ }^{25} \mathrm{CVR}$ strict was used in this study so that only the necessary options were kept in the CVR formula.

\section{Content validity index}

The CVI was promoted initially by Waltz and Bausell. ${ }^{26}$ Eight experts (the same individuals who participated in the CVR determination) were asked to confirm whether each item fits the four-point Likert scale (from absolutely relevant to irrelevant) in order to determine the content validity of each item and to ensure whether the items were designed properly to create the constructs.

The remaining items were sent back to the experts after the first round. This was done to find which items needed to be revised or eliminated, to know whether any further item is needed to completely cover the related concept, and to ensure that correct number of items was presented in all the aspects of each construct. Then, it was decided to revise or eliminate items based on its CVI level. The items with the score of 0.7 or less were candidates for elimination.

\section{Construct validity}

Construct validity is considered to be a factor in determining the questionnaire's efficiency in measuring the created constructs. Factor analysis was used to study the internal relationship between the variables and explore the categories of items that were closely related. ${ }^{27}$ Kaiser-Meyer-Olkin (KMO) and Bartlett sphericity tests were used before extracting the components to ensure that the items were appropriately designed to analyze the different factors. The KMO value of 0.7 or higher was considered as the condition for sample size sufficiency in the content analysis. Bartlett's test of sphericity was used to test the level of correlation between the questionnaire's items in a way that the merging of items is possible. The required sample size for content analysis varies from 5 to 10 for each item. ${ }^{28} \mathrm{~A}$ sample of 367 participants was used in this study for the exploratory content analysis. The exploratory factor analysis, analysis of the main components of the Scree plot to estimate the appropriate number of factors, eigenvalues equal to and/or greater than 1, and varimax rotation were used. The minimum factor loading of the present study was taken as $0.3 .{ }^{27}$

\section{Reliability}

The reliability of this study was verified using the internal consistency and stability methods. Cronbach's alpha was used in the internal consistency method, and the minimum alpha was considered to be $0.7 .^{29}$ The test-retest and intraclass correlation coefficient (ICC) were used to confirm the stability by asking 20 elderlies to fill the questionnaire twice with a 2-week interval. ICC is a test of reliability and a form of Cronbach's alpha which describes how strongly units in the same group resemble each other. The acceptable minimum for ICC was set at $0.7 .^{30}$

\section{Ethical considerations}

Each subject signed an informed consent form in accordance with the Declaration of Helsinki, and this study was approved by the local ethical committee of Babol University of Medical Sciences with the registration number MUBABOL. REC.1394.177. All the information was gathered without disclosing the identity of any of the participants, and they were ensured that the data were collected only for research purposes and was confidential.

\section{Results}

The panel members including 17 faculty members and clinical nurses, were $59 \%$ and $41 \%$, respectively. All the participants responded to the questionnaire at the first Delphi round. Sixty-one out of 74 items were accepted with an agreement level of 75 or more. Eight items were added as suggested. Of the panel members, $92 \%$ responded to the questionnaire at the second Delphi round. Five items were eliminated at this stage and 64 remained. Therefore, it was not necessary to conduct a third round of the Delphi.

The early item pool contained 64 items from the literature review. Six items were reviewed and qualitatively analyzed for validity and none of the items were eliminated, although four items receiving a score of 1.5 or less in quantitative validity analysis were eliminated. A 60 -item questionnaire remained.

Twelve items were reviewed in the content validity analysis and all the possible changes were applied. The quantitative survey of content validity was based on the CVR and CVI methods. Two items including "he/she says that I'm a moron and stupid" and "he/she says that I'm not sexually attractive" were eliminated using CVR method. Another item was also disregarded after receiving a score of 0.71 in CVI method. The mean content validity score for all the remaining items was equal to 0.93 in the next step.

A 57-item questionnaire based on a four-point Likert scale (4 for always and 1 for never) was prepared for the exploratory content analysis phase. It was given to 367 elderly 
patients on dialysis referred by the health centers located at the western region of Mazandaran province, Iran.

SPSS, version 21, software package was used to analyze the data. The KMO score was calculated to be 0.923 which indicated the sampling adequacy for performing factor analysis. Meanwhile, Bartlett's test of sphericity at 28,978.899 was significant at the 0.0001 level and 1,596 degrees of free$\operatorname{dom}(p=0.001)$, which justify the factor analysis based on correlation matrix of the sample and showed that the correlation matrix is not zero in the population. For extracting the factors in this research, the analysis of main components was used and for defining the number of factors, the eigenvalue was used. The results showed that $74.769 \%$ of the total variance was defined by the first seven factors. In other words, from among 57 indexes, five factors explained $74.769 \%$ of the changes in special values of each of the text indexes. Scree plot test results that determine the number of factors at this phase are shown in Figure 1.

The first component: This component included six items related to psychological misbehaviors. The highest load factor was observed for the item "He/she tries to instill fear in me by throwing or breaking my stuff," and the minimum was for the item "He/she doesn't care about my ability, knowledge, and experience in controlling the disease." The variance ratio for this component was calculated to be 41.103 .

The second component: Seven items were included in this component stating authority deprivation. The highest load factor was observed for the item "He/she changes my appearance without my will or acceptance," and the minimum was observed for the item "He/she prevents me from taking part in social activities like self-help groups or voluntary activities." The variance ratio for this component was calculated to be 59.779 .

The third component: This component included two items stating physical misbehavior. The highest load factor in this component was related to the item "He/she beats me with any excuse when my care and treatment needs increase," and the minimum load factor was related to the item " $\mathrm{He} / \mathrm{she}$ hurts me deliberately while moving me." The variance ratio for this component was calculated to be 64.183 .

The fourth component: This component included 11 items related to financial misbehavior. The highest load factor was observed for the item "He/she has changed my will without my family members and my own confirmation," and the minimum was for the item "He/she doesn't provide the basic needs like food or clothes regularly." The variance ratio for this component was calculated to be 67.683 .

The fifth component: This component included four items regarding being abandoned. The highest load factor was observed for the item "He/she doesn't accompany me going for hemodialysis or visiting the doctor," and the minimum was for the item "He/she has kicked me out of my home." The variance ratio for this component was calculated to be 70.264.

The sixth component: This component included nine items related to caring neglect. The highest load factor was observed for the item "He/she curses in doing outside jobs like buying goods or paying the bills" and the minimum was for the item "He/she doesn't help me in diagnosis or treatment

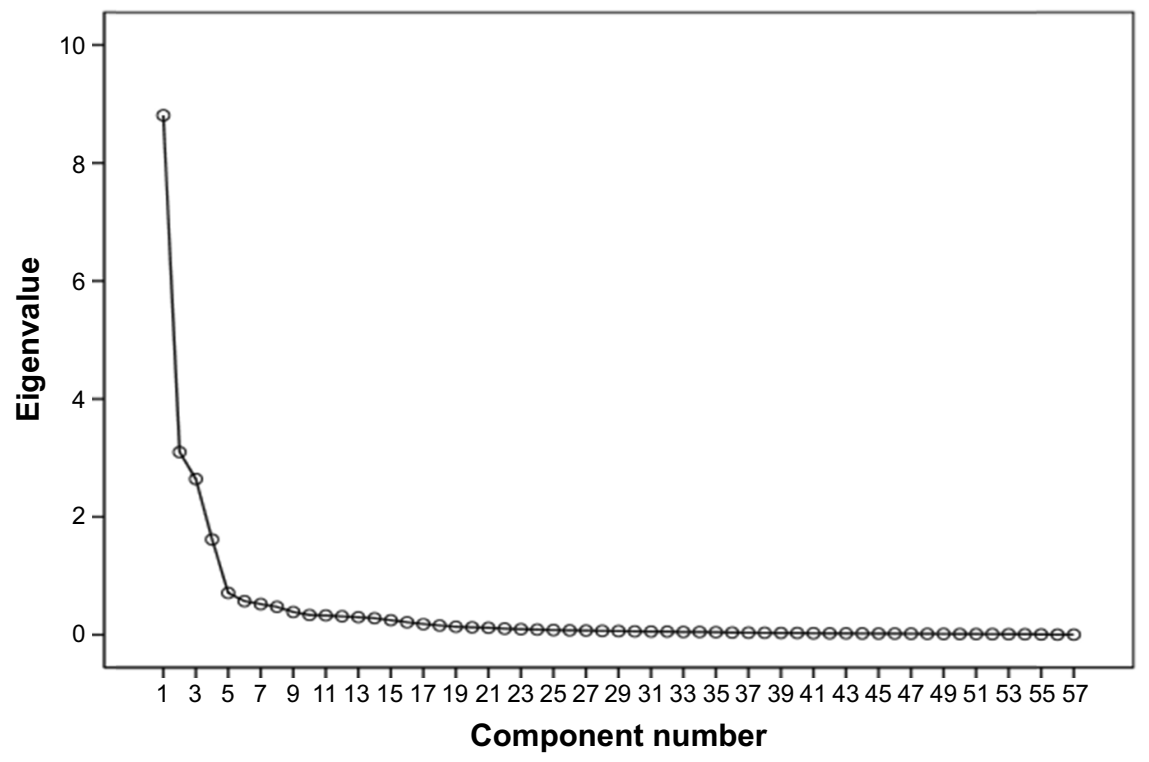

Figure I Scree plot in elder abuse by family caregivers among older adults on hemodialysis questionnaire. 
processes like going to the doctor, getting medical tests, or providing drugs." The variance ratio for this component was calculated to be 72.666 .

The seventh component: This component included 19 items related to emotional misbehaviors. The highest load factor was observed for the item "He/she says no one cares about me since I am old and ill" and the minimum was for the item "He/she tries to have the least physical contact with me fearing the transmission of infectious diseases like hepatitis." The variance ratio for this component was calculated to be 74.769. Rotated factor loadings of the elderly abuse by family caregivers among older adults on hemodialysis questionnaire and commonalities are shown in Table 1.
To evaluate the internal consistency, Cronbach's alpha was calculated for each item and for all the items together which was 0.98 . The test-retest method was used to test the stability. The results showed that the scores of the first and second tests were statistically significant $(p<0.001$ and ICC $=0.91$ ), confirming the stability of the subscales and the questionnaire as shown in Table 2.

The questionnaire included seven subscales including psychological misbehavior (1-6), authority deprivation (7-13), physical misbehavior $(14,15)$, financial misbehavior (16-26), being abandoned (27-30), caring neglect (31-38), and emotional misbehavior (39-57). The scoring scale in this questionnaire was based on a four-point Likert

Table I Rotated Component Matrix of the 57-item elder abuse by family caregivers among older adults on hemodialysis questionnaire (extraction method: Principal Component Analysis; rotation method: varimax with Kaiser normalization; a. Rotation converged in 7 iterations)

\begin{tabular}{|c|c|c|c|c|c|c|c|}
\hline \multirow[t]{2}{*}{ Items } & \multicolumn{7}{|c|}{ Component } \\
\hline & $\mathbf{I}$ & 2 & 3 & 4 & 5 & 6 & 7 \\
\hline $\mathrm{He} / \mathrm{she}$ threatens to leave me, shut me in, or cut the medical help & 0.793 & & & & & & \\
\hline $\mathrm{He} /$ she tries to instill fear in me by throwing or breaking my stuff & 0.915 & & & & & & \\
\hline He/she teases me by talking about my health problems with others & 0.842 & & & & & & \\
\hline He/she doesn't respect my personality & 0.852 & & & & & & \\
\hline He/she doesn't care about my ability, knowledge, and experience in controlling the disease & 0.723 & & & & & & \\
\hline He/she calls me improper names in an inappropriate tone in the presence of others & 0.876 & & & & & & \\
\hline $\begin{array}{l}\text { He/she prevents me from taking part in social activities like self-help groups or voluntary } \\
\text { activities }\end{array}$ & & 0.641 & & & & & \\
\hline $\begin{array}{l}\text { He/she prevents me from being in contact with my relatives like grandchildren, friends, } \\
\text { or family members }\end{array}$ & & 0.788 & & & & & \\
\hline He/she doesn't let me receive information on my disease from professionals & & 0.744 & & & & & \\
\hline He/she imposes his/her decision on selecting the health center or specialist & & 0.727 & & & & & \\
\hline He/she doesn't let me choose my living place & & 0.784 & & & & & \\
\hline He/she doesn't let me use my estate or properties to fund the treatment process & & 0.748 & & & & & \\
\hline He/she changes my appearance without my will or acceptance & & 0.868 & & & & & \\
\hline He/she hurts me deliberately while moving me & & & 0.638 & & & & \\
\hline He/she beats me and gives excuses when my care and treatment needs increase & & & 0.889 & & & & \\
\hline He/she borrows money from others for my treatment without my notice & & & & 0.940 & & & \\
\hline He/she doesn't return the money he/she has borrowed from me though I personally need it & & & & 0.629 & & & \\
\hline He/she imposes the daily expenses of caring for me on me though he/she has a good & & & & 0.951 & & & \\
\hline economic situation & & & & & & & \\
\hline He/she takes over my properties without my confirmation & & & & 0.921 & & & \\
\hline He/she doesn't pay my inheritance or let me use it & & & & 0.940 & & & \\
\hline He/she has received a power of attorney for taking over my properties & & & & 0.924 & & & \\
\hline He/she has changed my will without my family members and my own confirmation & & & & 0.958 & & & \\
\hline He/she doesn't provide the basics like foodstuffs or clothes regularly & & & & $0.41 \mathrm{I}$ & & & \\
\hline He/she disrespectfully helps me if I need money for the treatment process urgently & & & & 0.621 & & & \\
\hline He/she doesn't give me money for buying gifts or being with my friends & & & & 0.791 & & & \\
\hline He/she doesn't provide accommodation proportional to my dignity or treatment needs & & & & 0.912 & & & \\
\hline He/she has kicked me out of my home & & & & & 0.560 & & \\
\hline $\mathrm{He} /$ she leaves me alone at home and returns late & & & & & 0.805 & & \\
\hline He/she doesn't accompany me when I go for hemodialysis or to visit the doctor & & & & & 0.901 & & \\
\hline $\mathrm{He} / \mathrm{she}$ has left me alone and is not in contact even by phone calls & & & & & 0.621 & & \\
\hline $\begin{array}{l}\text { He/she doesn't help me in daily activities like bathing, going to the toilet, or cooking after the } \\
\text { hemodialysis }\end{array}$ & & & & & & 0.602 & \\
\hline $\begin{array}{l}\text { He/she doesn't help me in diagnosis or treatment processes like going to the doctor, getting } \\
\text { medical tests, or providing drugs }\end{array}$ & & & & & & 0.556 & \\
\hline
\end{tabular}


Table I (Continued)

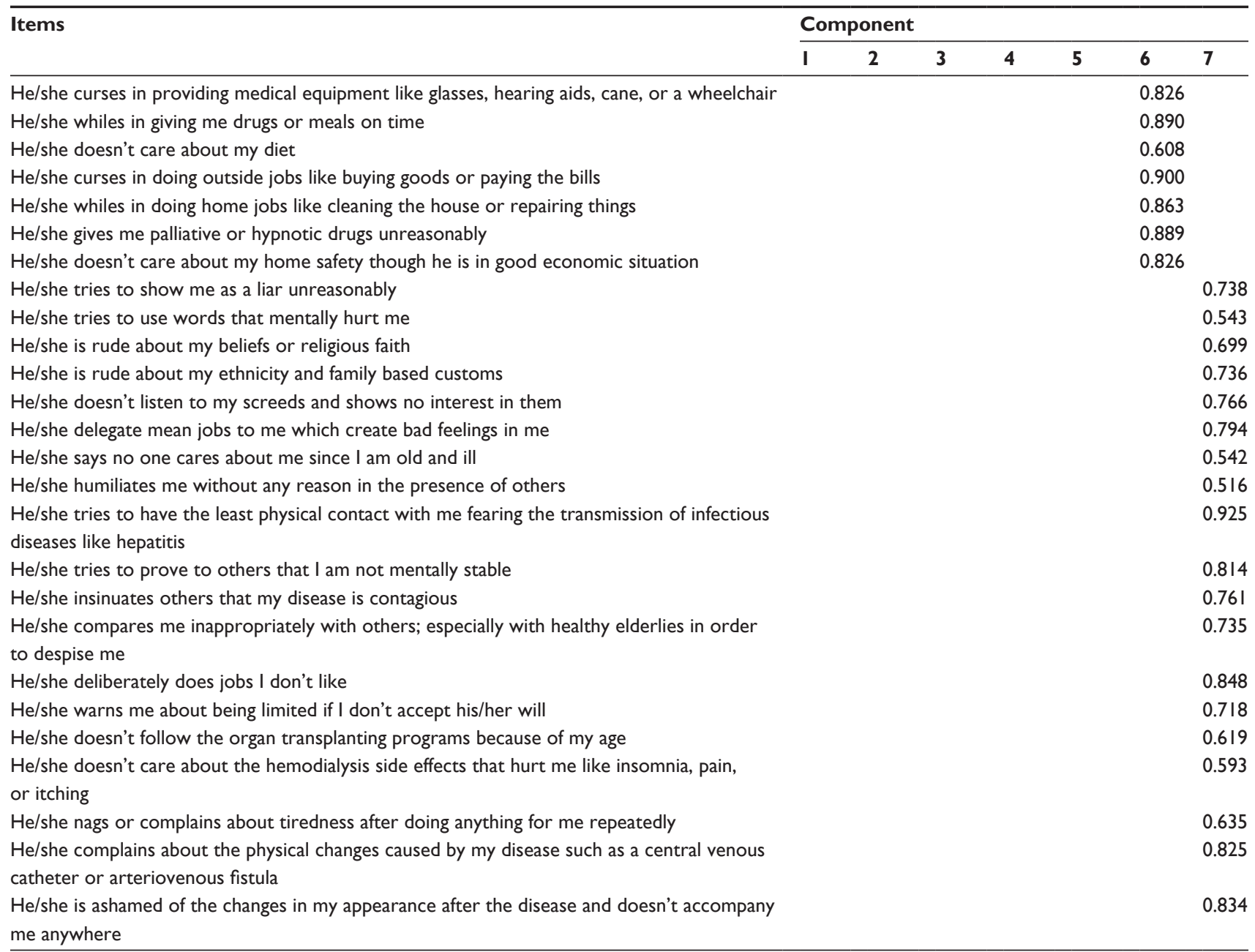

scale ranging from "always" with 4 to "never" with 1 . The total score varied from 1 to 228 , where the score $1-75$ denoted weak/slight elderly abuse by family caregivers, 76-152 denoted medium, and 153-228 denoted severe elderly abuse by family caregivers toward the elderlies on hemodialysis.

Table 2 The results of internal consistency evaluation of the questionnaire on elderly abuse by family caregivers of elderlies undergoing dialysis

\begin{tabular}{lllll}
\hline Factor & Subscale & Number & $\begin{array}{l}\text { Cronbach's } \\
\text { alpha }\end{array}$ & ICC \\
\hline I & Psychological misbehavior & $6(I-6)$ & 0.79 & 0.82 \\
2 & Authority deprivation & $7(7-13)$ & 0.88 & 0.89 \\
3 & Physical misbehavior & $2(14-15)$ & $0.8 I$ & 0.84 \\
4 & Financial misbehavior & II (I6-26) & 0.83 & 0.89 \\
5 & Being abandoned & $4(27-30)$ & $0.8 I$ & 0.86 \\
6 & Caring neglect & $9(3 I-38)$ & 0.79 & 0.84 \\
7 & Emotional misbehavior & $19(39-57)$ & 0.88 & 0.89 \\
Total & Overall questionnaire & 57 & 0.89 & 0.91 \\
\hline
\end{tabular}

Abbreviation: ICC, intraclass correlation coefficient.

\section{Discussion}

The present study involved the design and development of a questionnaire with 57 items and seven subscales on family caregivers' misbehavior toward elderlies on hemodialysis, and the questionnaire's reliability and validity were verified. This questionnaire showed acceptable content validity. The ratio of content validity to CVI was also appropriate. The exploratory factor analysis was applied to all the 57 items to determine the construct validity. The KMO scale and Bartlett test also approved the factor analysis model. The eigenvalues proved the multifactorial specification of the questionnaire. Each item showed a fair relationship with each of the subscales, and the structural validity degree of the mean correlation seemed to be reasonable as indicated by the factor loading of each item. The statistically significant relationship between the subscales and total score of the questionnaire was observed.

The reliability details of our study seem to be encouraging. The reliability of the scale was confirmed both by the internal consistency and retest methods, thus strengthening the 
reliability of the test results. The results showed that the questionnaire has good internal consistency. Heravi-Karimooi et al have also used the retest method with a 2 -week interval to confirm the stability of their elderly abuse questionnaire. ${ }^{31}$

Decreasing the number of the items of this questionnaire is possible as the internal consistency is sufficient and may make it easier to use.

This questionnaire, which we recommend as a mini scale, can be used both in statistical and practical studies. Nurses or other health care providers can use it in health centers, dialysis centers, or at the homes of patients. The face and content validities approve the simplicity and the clarity of the questionnaire though the illiteracy or low literacy of the majority of elderlies led to the researchers having to read the items to the elderlies in order to have the same manner of responding to each item in the psychometric process; still, the researchers believe that the items were designed to be easily understood and responded to by both literate and illiterate participants. The items of the sexual misbehavior component were eliminated by the expert panel members.

\section{Limitations}

Most of the elderlies accepting the participation verbally agreed about being sexually or physically abused. Whereas in filling the questionnaire, they refused such confessions due to religious considerations or cultural limitations.

\section{Acknowledgments}

We do appreciate all the older adults, nurses, and faculty members who helped us conduct this research.

\section{Disclosure}

The authors report no conflicts of interest in this work.

\section{References}

1. Zandi F, Fadaei F, editors. Victimization of Eldery: Proceedings of the Second Congress of Analysis of Geriatrics Issues in Iran. Tehran: Andisheh Cohan; 2008:571-587.

2. Annually Country Statistics. Tehran: Management and Planning Organization (PP.52e55). Tehran: Iranian Statistical Center; 2011.

3. Baghaie Lake M, Rahimi S, Adib M, Kazem Nejad Leili E, Monfared A. Redictive personal factors of quality of life in hemodialysis patient. J Holis Nurs Midwifery. 2015;24(4):9-19.

4. Tonelli M, Riella M. Chronic kidney disease and the ageing population. J Ren Care. 2014;40(1):1-5.

5. Jager K, Van Dijk P, Dekker F, Stengel B, Simpson K, Briggs J. The epidemic of aging in renal replacement therapy: an update on elderly patients and their outcomes. Clin Nephrol. 2003;60(5):352-360.

6. Kurella M, Covinsky KE, Collins AJ, Chertow GM. Octogenarians and nonagenarians starting dialysis in the United States. Ann Int Med. 2007;146(3):177-183.
7. Raiesifar A, Torabpour M, Mohsenizad P, Shabani H, Tayebi A, Masoumi M. Dialysis adequacy in patients of Abadan hemodialysis center. J Crit Care Nurs. 2009;2(3):87-90.

8. Sahaf R, Ilali ES. Uncertainty, the overbearing lived experience of the elderly people undergoing hemodialysis: a qualitative study. Int $J$ Community Based Nurs Midwifery. 2017;5(1):13.

9. Pouladi S, Anoosheh M, Kazemnejad A, Zareiyan A. Factors limiting families in elderly care: a thematic analysis. J Qual Res Health Sci. 2013; 2(2):146-157.

10. Taylor DK, Bachuwa G, Evans J, Jackson-Johnson V. Assessing barriers to the identification of elderly abuse and neglect: a communitywide survey of primary care physicians. J Natl Med Assoc. 2006;98(3):403.

11. Cooper C, Selwood A, Livingston G. The prevalence of elderly abuse and neglect: a systematic review. Age Ageing. 2008;37(2):151-160.

12. Von Heydrich L, Schiamberg LB, Chee G. Social-relational risk factors for predicting elderly physical abuse: an ecological bi-focal model. Int J Aging Hum Dev. 2012;75(1):71-94.

13. National Research Council. Elder Mistreatment: Abuse, Neglect, and Exploitation in an Aging America. Washington, DC: The National Academies Press; 2003.

14. Fulmer T, Paveza G, VandeWeerd C, et al. Dyadic vulnerability and risk profiling for elderly neglect. Gerontologist. 2005;45(4):525-534.

15. Laumann EO, Leitsch SA, Waite LJ. Elderly mistreatment in the United States: prevalence estimates from a nationally representative study. J Gerontol B Psychol Sci Soc Sci. 2008;63(4):S248-S254.

16. Heravi-Karimooi M, Anoosheh M, Foroughan M, Hajizadeh E, Sheykhi M. The meaning of domestic elderly abuse concept. J Daneshvar. 2010;17:39-51.

17. LoBiondo-Wood G, Haber J. Nursing research: methods and critical appraisal for evidence-based practice, 8th edition. St. Louis, Missouri: Elsevier; 2014.

18. Powell C. The Delphi technique: myths and realities. J Adv Nurs. 2003; 41(4):376-382.

19. Hsu C-C, Sandford BA. The Delphi technique: making sense of consensus. PARE. 2007;12(10):1-8.

20. Landeta J. Current validity of the Delphi method in social sciences. Technol Forecast Soc Change. 2006;73(5):467-482.

21. Windle PE. Delphi technique: assessing component needs. J Perianesth Nurs. 2004;19(1):46-47.

22. Hung H-L, Altschuld JW, Lee Y-F. Methodological and conceptual issues confronting a cross-country Delphi study of educational program evaluation. Eval Program Plann. 2008;31(2):191-198.

23. Culley JM. Use of a computer-mediated Delphi process to validate a mass casualty conceptual model. Comput Inform Nurs. 2011;29(5):272.

24. Shali M, Ghaffari F, Joolaee S, Ebadi A. Development and psychometric evaluation of the patient safety violation scale in medical oncology units in Iran. Asian Pac J Cancer Prev. 2016;17(9):4341-4347.

25. Lawshe $\mathrm{CH}$. A quantitative approach to content validity. Pers Psychol. 1975;28(4):563-575.

26. Waltz CF, Bausell BR. Nursing Research: Design, Statistics, and Computer Analysis. Philadelphia: F.A. Davis Co.; 1981.

27. Navabi N, Ghaffari F, Shamsalinia A, Faghani S. Development and validation of evaluation tools of nursing students' clinical pharmacology unit. Drug Healthc Patient Saf. 2016;8:101.

28. Knapp T, Brown J. Ten measurement commandments that often broken. Res Nurs Health. 1995;18(5):465-469.

29. Ghaffari F, Shali M, Shoghi M, Joolaee S. Psychometric properties of the Persian version of the self-assessed support needs questionnaire for breast cancer cases. APJCP. 2014;15(3):1435-1440.

30. Liang Y, Lau PW, Huang WY, Maddison R, Baranowski T. Validity and reliability of questionnaires measuring physical activity self-efficacy, enjoyment, social support among Hong Kong Chinese children. Prev Med Rep. 2014;1:48-52.

31. Heravi-Karimooi M, Anoosheh M, Foroughan M, Sheykhi MT, Hajizadeh E. Designing and determining psychometric properties of the Domestic Elderly Abuse Questionnaire. Iranian J Ageing. 2010; 5(1):7-12. 
Clinical Interventions in Aging

\section{Publish your work in this journal}

Clinical Interventions in Aging is an international, peer-reviewed journal focusing on evidence-based reports on the value or lack thereof of treatments intended to prevent or delay the onset of maladaptive correlates of aging in human beings. This journal is indexed on PubMed Central, MedLine,

CAS, Scopus and the Elsevier Bibliographic databases. The manuscript management system is completely online and includes a very quick and fair peer-review system, which is all easy to use. Visit http://www.dovepress. $\mathrm{com} /$ testimonials.php to read real quotes from published authors.

Submit your manuscript here: http://www.dovepress.com/clinical-interventions-in-aging-journal 